\title{
Psychotropic medication non-adherence among patients with severe mental disorder attending at Bahir Dar Felege Hiwote Referral hospital, north west Ethiopia, 2017
}

Daniel Ayelegne Gebeyehu', Haregewoin Mulat² ${ }^{2}$ Lulu Bekana ${ }^{3}$, Nega Tezera Asemamaw4, Mequanent Kassa Birarra ${ }^{5}$, Wubet Worku Takele ${ }^{1}$ and Dessie Abebaw Angaw ${ }^{6^{*}}$

\begin{abstract}
Objective: Medication non-adherence is a major public health problem that has been called an "invisible epidemic". Globally, non-adherence rates among patients with severe mental illness ranged between 30 and 65\%. It greatly increases the risk of illness exacerbation and hospitalizations. However, there is a paucity of studies examining treatment non-adherence and its associated factors among patients with severe mental disorder. Therefore, this study was aimed at determining the magnitude of medication non-adherence and associated factors among patients with severe mental disorder.

Results: A total of 409 study subjects were participated making a response rate of $92 \%$. The overall prevalence of medication non-adherence was found to be $55.2 \%$ (95\%, Cl; 49.9\%, 60.2\%). Study participants whose age group of (25-34) $[\mathrm{AOR}=3.04(95 \% \mathrm{Cl} 1.27,7.29)]$, study subjects taking their medication twice per day $[\mathrm{AOR}=4.60(95 \% \mathrm{Cl} 2.25$, 9.43)], no social support [AOR $=4.4(95 \% \mathrm{Cl} 1.78,11.08)]$ and no insight for their treatment $[\mathrm{AOR}=5.88(\mathrm{Cl} 2.08,16.59)]$ were significantly associated with medication non-adherence. The result of this study showed that non-adherence among patients with severe mental disorder was found to be high. Psychiatry health care providers have to consider the frequency of medication become once per day, continual awareness creation among professionals and engaging significant others for good social support system and continual treatment alliance is strongly commended for adherence.
\end{abstract}

Keywords: Medication non-adherence, Severe mental disorder, Ethiopia

\section{Introduction}

Currently, psychotropic medications are a vital component in the treatment of patients with severe mental disorders with the growing availability of a wide range of drugs to treat mental illnesses [1]. Based on the World Health Organization (WHO) definition of adherence, medication adherence is the extent to which a person's behavior-taking medications, following the diet, and/or

\footnotetext{
*Correspondence: dessieabebaw96@gmail.com

${ }^{6}$ School of Public Health, Department of Biostatistics and Epidemiology, College of Medicine and Health Sciences, University of Gondar, Gondar, Ethiopia

Full list of author information is available at the end of the article
}

executing lifestyle changes, corresponds with agreed recommendations of a healthcare provider [2, 3].

Medication non-adherence has serious consequences for individuals as well as in the country, having psychiatric disorders often resulting in 3.7 time's higher rates of relapse and exacerbation of psychotic symptoms, increased aggression and worse prognosis, more violent than adherent patients, higher hospitalization, and poorer community adjustment [4-7].

The problem of non-adherence is multi-factorial; some of which are, younger patients [8], being females, married, primary class education, unemployed [9], having perception being stigmatized, and the odds medication 
non-adherence is higher among substance, khat/'chat', alcohol and cigarette users [10].

In Ethiopia, there is a paucity of studies examining treatment non-adherence and its associated factors among patients with severe mental disorder in developing countries. Therefore, this study was aimed to assess the magnitude of medication non-adherence and to figure out the determinant factors. Furthermore, it would provide scientific evidence for local decision-makers, programmers and service planners to make an informed decision that would address the best interests of a patient with severe mental disorder leading to better health and quality of life.

\section{Main text Methods \\ Study design, study area and period}

An institutional-based cross-sectional study was conducted from June 01, 2017 to June 30, 2017, G.C in Felege Hiwot Referral Hospital, Bahir Dar, North West Ethiopia, a capital city of Amhara Regional State of Ethiopia. It is located $563 \mathrm{~km}$. far from Addis Ababa. According to the 2012 National population census, the city has a total of 549,429 populations [11]. From a report sheet, the average number of SMD patients who visit the outpatient department per month was 1100, among this 650, 200 and 250 are schizophrenic, bipolar and MDD, respectively.

\section{Study population, sample size determination and sampling techniques}

Patients with Schizophrenia, Bipolar and MDD who had at least two or more regular follow up at Bahir Dar Felege Hiwot Referral Hospital were included in the study. On the other hand, Individuals who were seriously ill, unable to respond to the interview and those who did not have family/caregiver were excluded.

The sample size was calculated using a single population proportion formula by considering the following statistical assumptions, the prevalence of medication non-adherence among adult psychiatric outpatient at Jimma was $41.2 \%$ [12], 95\% confidence interval, and 5\% degree of precision with a non-response rate of $10 \%$ which gives a total of 409 study participants.

The stratified sampling technique was employed. The proportional allocation was done basing the three disorders namely, Schizophrenia, Bipolar and MDD. Then after, the systematic random sampling technique was used to select study participants from each stratum.

\section{Study variables, data collection procedures and tools}

Psychotropic medication non-adherence was the dependent variable in which participants who were scored greater than or equal to 3 in 8-items of Morisky scale were considered as non-adherence [13, 14]. Social support was assessed using Oslo-3 Social Support Scale (OSS-3); interpretation was made as, a person scored 12-14 (good), 9-11 (moderate), and 3-8 (poor social support) [15]. Perceived internal stigma was considered when the patient who has scored one or more out of the 3-item instrument of screening perceived internal stigma [16].

Medication attitude inventory (DAI), a 10-item true/ false scale; was employed to assess beliefs about treatment. A correct answer scored as +1 , and an incorrect answer scored as -1 . The final DAI score is the sum of the pluses and minuses. A positive total score indicates a positive attitude towards medication, and a negative total score, a negative attitude [14].

Moreover, Insight was measured by using three item questions which were adopted from a study conducted in Nigeria, Africa. After checking its validity by taking a pre-test and modified it into our context. The interpretation was made as 1 was coded as yes and zero for no. The total score ranged between 0 and 3 . After summation of the scores, the interpretation was made based on; a score of zero is regarded as "no insight", a score of 1-2 is "partial insight", and a total score of 3 as "full insight" [17].

\section{Data quality assurance, data processing, and analysis}

The quality of data was assured by providing training for data collectors and supervisors, pretest and by translating the questionnaire into local language, Amharic. Data were checked for completeness and its consistency. After appropriate coding, the collected data has been entered into epiinfo version 7 and it was exported to SPSS version 23 for analysis. The Binary logistic regression model was fitted to control the effect of confounders; variables which had a $P$ value of less than 0.2 in the bi-variable model were entered to the multi-variable regression model. Finally, variables having a P-value of $<0.05$ at $95 \%$ $\mathrm{CI}$ in the multivariable binary logistic regression were considered as statistically significant.

\section{Results}

\section{Socio-demographic characteristics}

About half (50.7\%) of the study participants were male. The mean $( \pm \mathrm{SD})$ age of participants was $33( \pm 12.16)$ years with a range of 18 and 76 years. The majority $(40.3 \%)$ of the respondents were in the age category of 25-34 years. Among the total participants, about (81.4\%) were orthodox (49.3\%) single, and (35.5) can't read and write (Table 1). 
Table 1 Socio-demographic characteristics of patient with severe mental disorder attending at Bahir Dar Felege Hiwot hospital, outpatient psychiatric department, April 2017

\begin{tabular}{|c|c|c|}
\hline Variable & Frequency & Percentage \\
\hline \multicolumn{3}{|l|}{ Sex } \\
\hline Male & 191 & 50.7 \\
\hline Female & 186 & 49.3 \\
\hline \multicolumn{3}{|l|}{ Age } \\
\hline $18-24$ & 84 & 22.3 \\
\hline $25-34$ & 152 & 40.3 \\
\hline $35-44$ & 80 & 21.2 \\
\hline$\geq 45$ & 61 & 16.2 \\
\hline \multicolumn{3}{|c|}{ Mean age $33(s d \pm 12.16)$} \\
\hline \multicolumn{3}{|l|}{ Religion } \\
\hline Orthodox & 307 & 81.4 \\
\hline Muslim & 64 & 17.0 \\
\hline Protestant & 6 & 1.6 \\
\hline \multicolumn{3}{|l|}{ Marital status } \\
\hline Single & 186 & 49.3 \\
\hline Married & 129 & 34.2 \\
\hline Separated & 12 & 3.2 \\
\hline Divorced & 37 & 9.8 \\
\hline Windowed & 13 & 3.4 \\
\hline \multicolumn{3}{|l|}{ Educational status } \\
\hline Can't read and write & 134 & 35.5 \\
\hline \multicolumn{3}{|l|}{ Grade } \\
\hline $1-8$ & 84 & 22.3 \\
\hline $9-12$ & 82 & 21.8 \\
\hline Diploma and above & 77 & 20.4 \\
\hline
\end{tabular}

\section{Treatment-related and illness factors}

Related to clinical characteristics of the study participants, the greatest $(44.0 \%)$ numbers of participants were suffering from schizophrenia (Fig. 1). The vast majority 274 (72.7\%) of participants were taking their medication ones per day, whereas, 99 (23.9\%), and $3(0.8 \%)$ were two times and three times per day, respectively. Nearly two-thirds of participants 239 (63.4\%) were greater than 12 months on treatment follow up, the rest $68(18 \%)$ and $70(18.6 \%)$ had less than 6 and 6-12 months, respectively.

\section{Types of currently used medication and side effects experienced by the study participants}

In the types of medication currently used among patients with severe mental disorder, majority of them were taking typical antipsychotic and antidepressant 87 (23.1\%) (Additional file 1).
More than half (58.4\%) of the study participants have not experienced side effects to the medications. The most frequently occurred side effects were tiredness; excessive sleep and weight gain 25.5\% (Additional file 2).

\section{Healthcare and patient-related factors}

Concerning the consequences of non-adherence, about $232(61.5 \%)$ knew the consequences of medication non adherence. More than half 213 (56.5\%) of participants were not received health education about their treatment. Among the participants 167 (44.3\%) reported that the expense of medication is cheap, whereas, 81 (21.5) reported that expensive and the rest 129 (34.2\%) to get their medication freely.

Regarding substance use during the treatment period, $80.1 \%$ of the study participants had experiences of substance use. Among users, 20.3\%, 19.4\% and 9.6\% were used alcohol, chat and cigarette. However, $12.2 \%, 15.5 \%$ and $4.0 \%$ of the participants were multi-substance users that had chat and cigarette, chat and alcohol and all the three, respectively. More than half (57.6\%) of participants experienced skipping of their medication (Additional file 3).

\section{Patient/family related factors}

Nearly three out of ten (25.7\%) participants had perceived stigma. Of $45.9 \%$ had good social support and relation and (70\%) had a positive attitude towards their medication. Concerning insight, more than half (55.4\%) of the participants had good insight towards their illness and treatment (Additional file 4).

\section{Prevalence of medication non-adherence}

The overall prevalence of medication non-adherence was found to be $55.2 \%$ (95\%, CI; $49.9 \%, 60.2 \%$ ).

\section{Factors associated with medication non-adherence}

The odds of developing medication non-adherence among the age group of $(25-34)$ was $3.04 \quad(A O R=3.04$ (95\% CI 1.27, 7.29) times higher as compared to participants age older than 45 years.

The likelihood of having medication non-adherence among patients taking their medication twice per day was $4.6(\mathrm{AOR}=4.60(95 \% \mathrm{CI} 2.25,9.43)$ times higher as compared to those taking once per day.

The likelihood of medication non-adherence among patients who had no social support were about 4.44 $(\mathrm{AOR}=4.4$ (95\% CI 1.78, 11.08) times higher as compared to those participants who had good social support. 


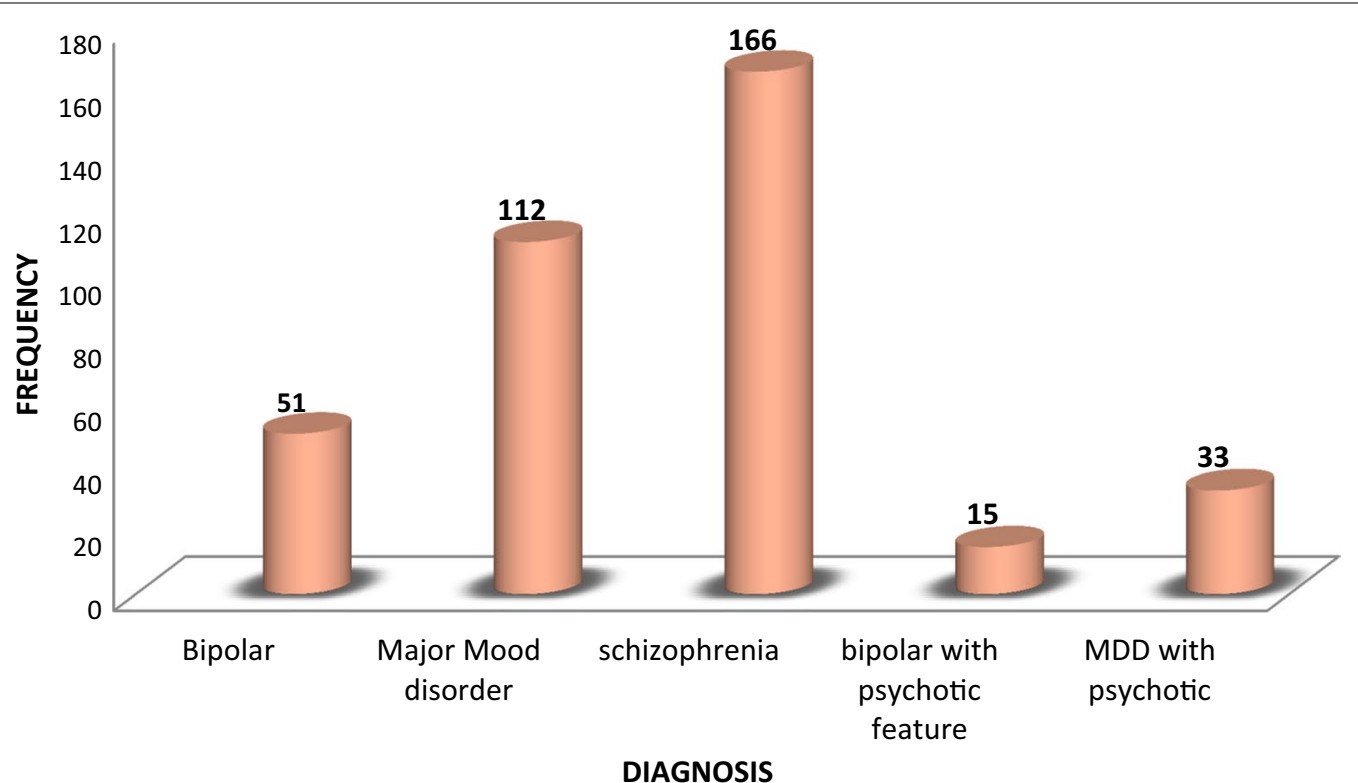

Fig. 1 Diagnosis among patients with severe mental disorder attending at Bahir Dar Felege Hiwot hospital, outpatient psychiatric department, April 2017

Table 2 Multivariable factors associated with medication non-adherence among patient with severe mental disorder attending at Bahir Dar Felege Hiwot hospital ( $\mathrm{n}=377)$

\begin{tabular}{llll}
\hline $\begin{array}{l}\text { Explanatory } \\
\text { variables }\end{array}$ & $\begin{array}{l}\text { Med. non } \\
\text { adherence }\end{array}$ & COR $(95 \% \mathrm{Cl})$ & AOR $(95 \% \mathrm{Cl})$ \\
\cline { 2 - 2 } & Yes No &
\end{tabular}

\begin{tabular}{lrrll}
\hline Age & & & & \\
$18-24$ & 44 & 40 & $1.29(0.67,2.51)$ & $1.34(0.53,3.44)$ \\
$25-34$ & 96 & 56 & $2.02(1.10,3.69)$ & $3.04(1.27,7.29)$ \\
$35-44$ & 40 & 40 & $1.18(0.60,2.29)$ & $2.45(0.93,6.59)$ \\
$\geq 45$ & 28 & 33 & 1 & 1 \\
Frequency of medication & & & \\
Once per day & 70 & 33 & 1 & 1 \\
Two times per & 138 & 136 & $2.09(1.29,3.37)$ & $4.60(2.25,9.43)$ \\
$\quad$ day' & & & & \\
Use of active substance & & & \\
Yes & 155 & 145 & $0.48(0.28,0.82)$ & \\
No & 53 & 24 & 1 & \\
Social support & & & & \\
Poor & 128 & 80 & $3.54(1.92,6.51)$ & $4.44(1.78,11.08)$ \\
Intermediate & 61 & 47 & $2.87(1.48,5.56)$ & $3.39(1.28,9.04)$ \\
Good & 19 & 42 & 1 & 1 \\
Attitude towards medication & & & \\
Positive & 132 & 132 & 1 & \\
Negative & 76 & 32 & $0.42(0.31,0.77)$ & \\
Insight & & & & \\
No & 55 & 8 & $12.28(5.55,27.16)$ & $5.88(2.08,16.59)$ \\
Partial & 78 & 27 & $5.16(3.07,8.69)$ & $2.88(1.38,6.01)$ \\
Good & 75 & 134 & 1 & 1 \\
\hline
\end{tabular}

The odds of medication non-adherence among patients who had no insight for their treatment were about six $(\mathrm{AOR}=5.88(\mathrm{CI} 2.08,16.59)$ folds higher as compared to their counterparts (Table 2).

\section{Discussion}

Typically, patients with a psychiatric disorder, almost in all have a major problem following a medication regimen $[18,19]$. So, this study examined the magnitude of psychotropic medications non-adherence and its associated factors among patients with severe mental disorder.

The current study found that $55.2 \%$ of patients with a severe mental disorder were non-adhere with their medication. This finding was in line with global non-adherence rates among patients with severe mental illness between 30 and $65 \%$ [20, 21]. This finding was also consistent with a study conducted in Nigeria 54.2\% [22], and 55.7\% [17]. However, lower than Pakistan's study (64.75\%) [8]. This variation could be the differences in socio-demography of the study population, selection criteria for the study participants and the lower sample size were taken in Pakistan, such as a convenient, non-probability sample of one hundred and thirty-five follow-up patients were assessed [8]. The non-adherence rate in the present study was found to be further an up than a report from in Jimma, Ethiopia 41.2\% [12], and India 26\% [23]. This discrepancy could result from the methodological differences in the studies, such as the tools used for the assessment of adherence. In Jimma, i.e. Morisky 4 item scale was used and health care services. 
This study comes up with psychotropic medication non-adherence was significantly associated with the age group of 25-34 years. This finding is in agreement with studies conducted in Qatar [24], India [25] and USA [26]. This might be being younger is prone a patient not to adhere the medication by considering the negative attitudes towards the medication as well the illness. It is also supported by; that individuals who have a negative perception towards their medication perceive themselves to have a capacity to control or manage their problem on their own [27].

This study was revealed that participants who were taking their medication twice daily were significantly associated with non-adherence. It was also in line with the study conducted in Ethiopia [12], Nigeria [22], India [25] and USA [26]. This might be due to forgetting to take their medication, fear of side effects and the discomfort arising from the high 'pill burden' fear of pill overload [17].

Regarding social support, participants who had no social support were significantly associated with nonadherence. This finding was supported by the study reported in Ethiopia [28], Nigeria [29], and USA [30, 31]. The possible explanation for this might be having social support as a cue to alarm them to take their medication on time, by minimizing fear that was related to medication side effects and by educating them the consequence of medication non-adherence.

Patients who had no insight into their disorder and treatment were significantly associated with medication non-adherence. This result is also similar to the study reported in Nigeria [28] India [25, 32, 33], USA [34] and Germany [35]. The possible explanation for this might be having or presence of insight towards the disease and their treatment plays an important role in medication adherence.

\section{Conclusion}

The result of this study showed that non-adherence among patients with severe mental disorder was found to be high. Psychiatry health care providers have to consider the frequency of medication become once per day, continual awareness creation among professionals and engaging significant others for good social support system and continual treatment alliance is strongly commended for adherence.

\section{Limitations of the study}

The limitation of this study might be affected by recall bias. This might distort the actual outcome.

\section{Additional files}

Additional file 1. Types of medication currently used among patients with severe mental disorder attending at Bahirdar Felege Hiwot hospital, outpatient psychiatric department, April 2017.

Additional file 2. Side effects profile self-reported by patient with severe mental disorder attending at Bahirdar Felege Hiwot hospital, outpatient psychiatric department, April 2017

Additional file 3. Reason for psychotropic medication non-adherence among patients with severe mental disorder attending at Bahirdar Felege Hiwot hospital, outpatient psychiatric department, April 2017.

Additional file 4. Patient/family related factors of patient with severe mental disorder attending at Bahirdar Felege Hiwot hospital, outpatient psychiatric department, April 2017.

\section{Abbreviations}

AMSH: Amanuel Mental Specialized Hospital; BPD: bipolar disorder; Cl: confidence interval; COR: crude odds ratio; OPD: out patient department; OR: odds ratio; UOG: University of Gondar; WHO: World Health Organization.

\section{Authors' contributions}

DAG: conception of the idea; designed of the study, conducted the study, data analysis and manuscript preparation. HM and LB were participating throughout the paper from proposal development, analysis, interpretation of the data, and manuscript preparation. NTA, MKB, WWT and DAA: analysis of data and developed the final version of the manuscript. All authors read and approved the final manuscript.

\section{Author details \\ ${ }^{1}$ School of Nursing, Department of Community Health Nursing, College of Medicine and Health Sciences, University of Gondar, Gondar, Ethio- pia. ${ }^{2}$ School of Medicine, Department of Psychiatry, College of Medicine and Health Sciences, University of Gondar, Gondar, Ethiopia. ${ }^{3}$ Amanuel Mental Health Specialized Hospital, Addis Ababa, Ethiopia. ${ }^{4}$ School of Nurs- ing, Department of Pediatric and Child Health Nursing, College of Medicine and Health Sciences, University of Gondar, Gondar, Ethiopia. ${ }^{5}$ School of Phar- macy, Department of Clinical Pharmacy, College of Medicine and Health Sciences, University of Gondar, Gondar, Ethiopia. ${ }^{6}$ School of Public Health, Department of Biostatistics and Epidemiology, College of Medicine and Health} Sciences, University of Gondar, Gondar, Ethiopia.

\section{Acknowledgements}

We authors would like to express our deepest sincerely gratitude for data collectors and psychiatry department staff for their efforts exerted on the realization of this study. In addition, our foremost appreciation also goes to the study participants for their voluntary participation in the study.

The authors appreciate the data collectors as well as the study participants.

\section{Competing interests}

The authors declare that they have no competing interests.

\section{Availability of data and materials}

All data generated or analyzed during this study are included in this published article. The data sets used and/or analyzed during the current study are available from the corresponding author on reasonable request.

\section{Consent for publication}

Not applicable.

Ethics approval and consent to participate data

Ethical clearance was obtained from University of Gondar and Amanuel Mental Specialized Hospital ethical committee. Written informed consent was obtained from participants and for those who had not full insight caregiver written informed consent was taken. They were informed that participation 
was on voluntary bases and have full right to withdraw at time of need during the interview process. Moreover, the researcher was motivated to protect and to respect the privacy, secrecy, and wellbeing of persons with these conditions. The data that was collected for the purpose of this study didn't contain identifying information, thus ensuring the secrecy of the participants. The entire data collected was used for the purpose of the current study only.

\section{Funding organization}

The study was funded by the University of Gondar and Amanuel Mental Specialized Hospital and the funders only involved by giving the funding.

\section{Publisher's Note}

Springer Nature remains neutral with regard to jurisdictional claims in published maps and institutional affiliations.

Received: 22 December 2018 Accepted: 9 February 2019

Published online: 26 February 2019

\section{References}

1. Dutt L, Mistry K, Zankhanjetfire M. A study of reasons of non-compliance to psychiatric treatment. Indian J Appl Basic Med Sci. 2016;18(26):15-23.

2. De Geest $\mathrm{S}$, Sabaté E. Adherence to long-term therapies: evidence for action. Eur J Cardiovasc Nurs. 2003;2(4):323.

3. Nichols-English G, Poirier S. Optimizing adherence to pharmaceutical care plans. Japha-Washington. 2000;40(4):475.

4. Cutler DM, Everett W. Thinking outside the pillbox-medication adherence as a priority for health care reform. N Engl J Med. 2010;362(17):1553-5.

5. Higashi K, Medic G, Littlewood KJ, Diez T, Granström O, De Hert M. Medication adherence in schizophrenia: factors influencing adherence and consequences of nonadherence, a systematic literature review. Ther Adv Psychopharmacol. 2013;3(4):200-18.

6. Morken G, Widen JH, Grawe RW. Non-adherence to antipsychotic medication, relapse and rehospitalisation in recent-onset schizophrenia. BMC Psychiatry. 2008:8(1):32.

7. Fenton WS, Blyler CR, Heinssen RK. Determinants of medication compliance in schizophrenia: empirical and clinical findings. Schizophr Bull. 1997;23(4):637-51.

8. Taj F, Tanwir M, Aly Z, Khowajah AA, Tariq A, Syed FK, et al. Factors associated with non-adherence among psychiatric patients at a tertiary care hospital, Karachi, Pakistan: a questionnaire based cross-sectional study. J Pak Med Assoc. 2008:58(8):432.

9. Rabinovitch M, Béchard-Evans L, Schmitz N, Joober R, Malla A. Early predictors of nonadherence to antipsychotic therapy in first-episode psychosis. Canadian J Psychiatry. 2009;54(1):28-35.

10. Rodenhauser P, Schwenkner CE, Khamis H. Factors related to drug treatment refusal in a forensic hospital. Psychiatric Serv. 1987;38(6):631-7.

11. Report. ECSAEO. 2013.

12. Tesfay K, Girma E, Negash A, Tesfaye M, Dehning S. Medication nonadherence among adult psychiatric out-patients in Jimma University specialized hospital, Southwest Ethiopia. Ethiop J Health Sci. 2013;23(3):227-36.

13. Morisky DE, Ang A, Krousel-Wood M, Ward HJ. Predictive validity of a medication adherence measure in an outpatient setting. J Clin Hypertens. 2008:10(5):348-54.

14. Hogan TP, Awad A, Eastwood R. A self-report scale predictive of drug compliance in schizophrenics: reliability and discriminative validity. Psychol Med. 1983;13(1):177-83.

15. Dalgard O. Social support-consequences for individual and society. EUPHIX, EUphact Bilthoven: RIVM, <http://www.euphix.org> EUphact〉

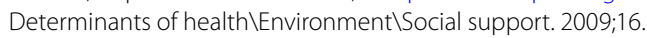

16. Sartorius N, Janca A. Psychiatric assessment instruments developed by the World Health Organization. Soc Psychiatry Psychiatr Epidemiol. 1996:31(2):55-69.
17. Ibrahim AW, Yahya S, Pindar SK, Wakil MA, Garkuwa A, Sale S. Prevalence and predictors of sub-optimal medication adherence among patients with severe mental illnesses in a tertiary psychiatric facility in Maiduguri, North-eastern Nigeria. Pan Afr Med J. 2015;21:1.

18. Mibei F. Noncompliance to medication in psychiatric patients: a literature review. 2013.

19. Billups SJ, Malone DC, Carter BL. The relationship between drug therapy noncompliance and patient characteristics, health-related quality of life, and health care costs. Pharmacotherapy. 2000;20(8):941-9.

20. Yang J, Ko Y-H, Paik J-W, Lee M-S, Han C, Joe S-H, et al. Symptom severity and attitudes toward medication: impacts on adherence in outpatients with schizophrenia. Schizophr Res. 2012;134(2-3):226-31.

21. Kassis IT, Ghuloum S, Mousa H, Bener A. Treatment non-compliance of psychiatric patients and associated factors: are patients satisfied from their psychiatrist? Br J Med Med Res. 2014;4(2):785.

22. Ibrahim A, Pindar S, Yerima M, Rabbebe I, Shehu S, Garkuwa H, et al. Medication-related factors of non adherence among patients with schizophrenia and bipolar disorder: outcome of a cross-sectional survey in Maiduguri, North-eastern Nigeria. J Neurosci Behav Health. 2015;7(5):31-9.

23. Shoib S, Mushtaq R, Dar MM, Mir JA, Shah T, Singh R, et al. Psychosocial and medical factors affecting treatment compliance in patients attending psychiatric hospital: a study from Kashmir. Int J Basic Clin Pharmacol. 2017:3(1):220-4.

24. Bener A, Dafeeah EE, Salem MO. A study of reasons of non-compliance of psychiatric treatment and patients' attitudes towards illness and treatment in Qatar. Issues Men Health Nurs. 2013;34(4):273-80.

25. Maan C, Hussain M, Heramani N, Lenin R. Factors affecting non-compliance among psychiatric patients in the regional institute of medical sciences. Imphal IOSR J Pharm. 2015;5:01-7.

26. Sajatovic M, Valenstein M, Blow FC, Ganoczy D, lgnacio RV. Treatment adherence with antipsychotic medications in bipolar disorder. Bipolar Disord. 2006;8(3):232-41.

27. Hou R, Cleak V, Peveler R. Do treatment and illness beliefs influence adherence to medication in patients with bipolar affective disorder? A preliminary cross-sectional study. Eur Psychiatry. 2010;25(4):216-9.

28. Chukwujekwu CD, Adesokun OK. Prevalence of medication non-adherence among psychiatric patients in a tertiary hospital in Nigeria. J Biosci Med. 2017;5(04):1

29. Adewuya AO, Owoeye OA, Erinfolami AR, Coker AO, Ogun OC, Okewole $A O$, et al. Prevalence and correlates of poor medication adherence amongst psychiatric outpatients in southwestern Nigeria. Gen Hosp Psychiatry. 2009;31(2):167-74.

30. Hudson TJ, Owen RR, Thrush CR, Han X, Pyne JM, Thapa P, et al. A pilot study of barriers to medication adherence in schizophrenia. J Clin Psychiatry. 2004;65(2):211-6.

31. Wilk JE, West JC, Marcus SC, Countis L, Regier DA, Olfson M. Family contact and the management of medication non-adherence in schizophrenia. Commun Ment Health J. 2008;44(5):377-80.

32. Roy R, Jahan M, Kumari S, Chakraborty P. Reasons for drug non-compliance of psychiatric patients: a centre based study. J Indian Acad Appl Psychol. 2005;31(1-2):24-8.

33. Tharani AJ, Faroog S, Saleem F, Naveed A. Compliance to antipsychotic medication: a challenge for client, family and health care providers. J Pak Med Assoc. 2013;63(4):516-8.

34. Bellack AS, Bowden CL, Bowie CR, Byerly MJ, Carpenter WT, Copeland $L A$, et al. The expert consensus guideline series: adherence problems in patients with serious and persistent mental illness. J Clin Psychiatry. 2009;70(SUPPL. 4):1-48.

35. Rummel-Kluge C, Schuster T, Peters S, Kissling W. Partial compliance with antipsychotic medication is common in patients with schizophrenia. Aust N Z J Psychiatry. 2008;42(5):382-8. 